\title{
LOS LÍMITES DE LA ACCIÓN SOCIAL EN LA ESPAÑA DEL SIGLO XIX ASISTENCIA Y SALUD PÚBLICA EN LOS ORÍGENES DEL ESTADO LIBERAL*
}

\author{
por \\ CarLes Grabuleda I TeIXIDOR \\ Universitat Pompeu Fabra
}

RESUMEN: En este articulo se trata de explicar la forma en que fueron discutidas y aprobadas las primeras leyes sociales en la España del siglo XIX. Después de la Revolución Liberal, el sistema aristencial del Antiguo Régimen, basado en la caridad eclesiástica, llegó a su fin. Los nuevos gobernantes tuvienon que establecer un nuevo sistema, teniendo en cuenta no solamente los cambios sociales y politicos sino también los cambios económicos derivados de las revoluciones del momento. No babía una única opción politica para afrontar estos cambios. No solamente babia discrepancias entre los dos partidos liberales sino incluso entre las diversas facciones de cada partido. Los debates parlamentarios que dieron lugar a las leyes de Beneficencia (1849) y de Sanidad (1855) son una buena muestra de la forma en que estas discusiones marcaron el expiritu del liberalismo español que entonces comenzaba a perfilarse.

Palabras clave: España. Legislación. Beneficencia. Sanidad. Política. Siglo XIX.

ABSTRACT: This article tries to explain bow the first welfare laws were enacted in nineteenthcentury Spain. After the Liberal Revolution, the Ancien Régime's system of social assistance, based on poor relief by the Church, came to an end. The new rulers needed to establish a new system, bearing in mind not only the social and political change, but also the economic changes resulting from the industrial and liberal revolutions. There was not a single solution accepted by everyone. There were disagreements not only between the two liberal parties (moderate and progressive), but also witbin each party. The parliamentary debates on the welfare and bealth acts

\footnotetext{
* La realización de esce trabajo fue posible gracias a la ayuda económica concedida por el Comissionat per a Universitats $;$ Recerca, de la Generalitat de Catalunya.
} 
of 1849 and 1855 were clear examples of bow these discussions reflected the spirit of the emerging Spanish liberalism.

KEY WORDS: Welfare. Health. Social security. Liberal revolution.

La política social de los estados europeos de finales del siglo XIX se ha venido interpretando como una novedad radical respecto al individualismo liberal hegemónico en la primera mitad del siglo, como fruto directo de la industrialización, las luchas obreras y la acción de las burguesías frente a estas. En el Estado español, se ha afirmado, se llegó a ella con un considerable retraso, porque no fue hasta principios del siglo XX cuando se desarrolló una auténtica política social. Argumentos como este tienden a ser simplificadores en exceso. La no vertebración de una política intervencionista sobre el trabajo fabril hasta el siglo XX (horarios de trabajo, descansos, accidentes, seguridad y previsión, etc.) no significa que los gobiernos de los decenios anteriores no se preocupasen en absoluto por las condiciones de vida de la población. La política social de nuestro siglo no puede ser estudiada como algo nuevo sino como una más de las muchas formas en que, a lo largo de la historia, se han concretado las preocupaciones de los gobernantes por la estabilidad de la población. Desde esta perspectiva es erróneo valorar la política liberal española exclusivamente como una rémora del Antiguo Régimen, como fruto de la acción de elementos retrógrados, porque es perfectamente comparable a la de otros estados europeos. Más bien hay que valorar las diversas variedades y cronologías de implantación como formas de adaptación a las diferentes realidades de cada estado. En las páginas que siguen trataré de mostrar cómo y en qué medida el Estado liberal de la primera mitad del siglo XIX se enfrentó a estos problemas desde una perspectiva benéfico-asistencial, y como la forma en que ello se concretó implicó situar la acción social española entre unos límites muy concretos' ${ }^{1}$.

I En este artículo no nos referiremos a la acción legislativa relacionada directamente con temas laborales, que no se consolidó hasta finales de siglo y que ya recibió atención en otros trabajos, entre los que cabe citar los de MARTín VALVERDE, Antonio, ed.: La legislación social en la Historia de España. De la Revolución Liberal a 1935, Madrid, Congreso de los Diputados, 1987; y ALARCón CARACUEL, M.: El derecbo de asociación obreta en España, 1839-1900, Madrid, 1975. El estudio de un caso concreco en Garcís PAYA, R. - SAfZ NúNEZ, J.: Los movimientos sociales del siglo XIX en Alcoi, originados por las condiciones de trabajo (seguridad e bigiene). Legislación existente, in Arqueologia industrial. Actes del Primer Congrés del Pais Valencià, València, Diputació de València, 1991. Muy interesante el reciente estudio de CaBriLlo, Francisco: Insdustrialización y derecho de daños en la España del siglo XIX, in "Revista de Historia Económica», 3, año XII, Madrid, 1995. Otros trabajos abordan el tema desde perspectivas diferentes. Cabe destacar MONTERo Garcín, Feliciano: Origenes y antecedentes de la previsión social. Los segaros saciales en la España del siglo XIX, Madrid, Ministerio de Trabajo y Seguridad Social, 1988; PALACio MORENA, J.I.: La institucionalización de la Reforma Social en España (1883-1924). La Comisión y el Instituto de Reformas Sociales, Madrid, Ministerio de Trabajo, 1989; y DE LA CALLE, M. D.: La Comisión de Reformas Saciales, 1883-1903. Politica sacial y conflicto de intere- 
En primer lugar, es preciso advertir del riesgo de mitificar los gobiernos ilustrados del siglo XVIII, error harto frecuente que nos lleva a valorarlos como punto de partida de este tipo de preocupaciones. De acuerdo con Carmen López Alonso, su acción retomaba muchos elementos desarrollados anteriormente: el cambio fundamental de la política reformista borbónica en este aspecto no fue más que una intensificación cuantitativa y cualitativa de la acción benéfica anterior, en relación a los intentos del Estado por tomar la iniciativa en unos temas que hasta entonces gestionaban la Iglesia y los municipios ${ }^{2}$. Por otro lado, cabría esforzarse en captar las diferencias entre la acción de los gobiernos de finales del XVIII y la política liberal decimonónica. En este sentido, sólo en parte parece acertado lo que se ha venido argumentando sobre el papel de las desamortizaciones en el contexto de la Revolución Liberal como punto final del sistema asistencial tradicional, basado en la acción eclesiástica. El proceso desamortizador, por un lado, es previo al inicio del ciclo revolucionario. Por otro lado, hay que evitar caer en el error frecuente de confundir absolutamente el anticlericalismo, y la antirreligiosidad incluso, de algunos sectores liberales, con un proceso desamortizador motivado fundamentalmente por imperativos hacendísticos. Aunque la Revolución implicó una pérdida enorme de recursos para la Iglesia, no se desarrolló de forma que significara la laicización total del ramo. Desde muchos sectores se procuró que el sistema edificado a partir de entonces, de base estatal pero patronado por la Iglesia, fuera un calco del anterior. El Estado, fuese por conveniencia económica, práctica o ideológica, evitó modificar en la medida que pudo, los esquemas precedentes. En cualquier caso, es innegable que, en un primer momento, en periodos muy concretos (1820-23, 1836), se actuó firmemente contra las órdenes religiosas y, por lo tanto, contra las principales instituciones benéficas particulares. Pero, siguiendo un proceso aún poco conocido, la virulencia y el intervencionismo liberales de los primeros tiempos se autocontroló hasta el punto que el sistema que se acabó consolidando a partir de 1849 , con la nueva Ley de Beneficencia (en total sintonía con los términos del Concordato que se firmaría poco después con

ses en la España de la Restautración, Madrid, Ministerio de Trabajo, 1989. Otros trabajos tratan aspectos puntuales sobre beneficencia. Ver BADENES GASSET, R: Legislación sobre beneficencia particular, Barcelona, Bosch, 1962, (2a. ed.); PILAR Mañas, J.L. - REAl PÉRez, A., Eds.: Legislación sobre instituciones de beneficencia particular. Fundaciones benéfico-asistenciales puras y mixtas, Madrid, Ministecio de Trabajo y Seguridad Social, 1987; BLANCo RUIZ, J.F.: El protectorado de fundaciones en el Real Decreto e Instrucción de 14 de marzo de 1899, Madrid, Ministerio de Trabajo y Seguridad Social, 1987.

2 LÓPEZ ALONSO, C.: La acción pública no estatal, in Historia de la accíbn social pública en España. Beneficencia y previsión, Madrid, Ministerio de Trabajo y Segucidad Social, 1990. Sobre el siglo XVIII, limitado a aspectos sanitarios, ZARzoso ORELlaNA, Alfons: Prevencí epidemica $i$ salut pública a la Barcelona del segle XVIII, Trabajo de doctorado inédito, Barcelona, Institut Univ. d'Història «Jaume Vicens Vives» - Univ. Pompeu Fabra, 1994 
la Santa Sede) restauraría la preeminencia eclesiástica y particular en la gestión benéfica que los primeros liberales combatieron ${ }^{3}$.

Por otro lado, habría que ver hasta que punto el gran incremento de producción legislativa que se produjo en el nuevo Estado liberal respondía a cambios en la acción concreta de la administración pública y si esta evolucionó por igual en todos sus ámbitos. El nivel de transformación y la filosofía con que se hizo frente a la "cuestión social» en los municipios de la Cataluña industrial no tiene porque ser el mismo, por ejemplo, que el de las ciudades castellanas o el de las propias estructuras del Estado central. En la Cataluña industrial, por ejemplo, parece claro que se pretendió regular la implantación de industrias, así como las condiciones higiénicas y de seguridad en las mismas, a partir de la legislación benéfico-sanitaria. En cualquier caso, esta forma de actuar implicaba unas limitaciones muy claras que sólo hubieran podido ser superadas por otro tipo de política social que, por razones obvias, las clases dirigentes se negaron a adoptar. Un repaso a la evolución legislativa en las primeras décadas del liberalismo español permitirá enmarcar los puntos centrales del tema.

\section{Legislación bentfico-SANITARIA EN la ESPaÑa liberal. PRINCIPALES DISPOSICIONES}

El sistema sanitario español, en las primeras décadas del siglo XIX, venía regulándose por un cúmulo de pequeñas disposiciones, muchas de ellas heredadas de la administración borbónica del siglo anterior. La Novísima Recopilación, (libro 7, título 40), se refería ya a temas de salud pública. La ley de 6 de octubre de 1751 dictaba preceptos para evitar el uso de ropas y efectos de enfermos contagiosos; la de $\mathbf{3 0}$ de junio de 1757 regulaba la venta de compuestos químicos y fármacos en tiendas públicas. La guerra de $1808-1814$ y la experiencia constitucional que comportó no supusieron, de momento, grandes cambios. Si exceptuamos el efímero decreto de 8 de junio de 1813, que permitía el libre establecimiento de fábricas y oficios, con el objetivo explícito de "Remover las trabas que basta abora ban entorpecido el progreso de la industria", y

3 Una interpretación interesante, aunque cuestionable en algunos aspectos, de esta transición en CARASA SOTO, Pedro: Beneficencia y control social en la España contemporánea, in BERGALU - MARI, Eds.: Historia ideologica del control social, Barcelona, PPU, 1989.

4 A mi modo de ver, esta es la interpretación que impone el estudio del caso concreto de Sant Martí de Provençals, pequeño núcleo rural vecino a Barcelona que en la segunda mitad del siglo experimentó un vertiginoso proceso de industrialización y suburbialización. Aunque hay que tener en cuenta que las dificultades de extrapolación a partir de un caso tan parcicular y la escasez de estudios parecidos en la región, no me parece arriesgado interpretarlo en este sentido. (Vid. GraBU. LEDA I TEIXIDOR, Carles: Treballadors, assistència $i$ salut pública a tentorn industrial de Barcelona. Sant Marti de Provençals, 1850-1900, Trabajo de doctorado inédito, Barcelona, Institut Univ. d'Història "Jaume Vicens Vives" - Univ. Pompeu Fabra, 1995) 
otras medidas puntuales', la verdadera acción legislativa reguladora del ramo no se produjo hasta el periodo de relativa estabilidad que se abrió con la Década Moderada. El Reglamento de 26 de marzo de 1847, sobre Juntas de Sanidad, el de 24 de julio de 1848, que creaba el cuerpo de Subdelegados de Sanidad, encargados de los trabajos de inspección, así como la Ley de 20 de mayo de 1854, sobre anuncios de medicamentos e intrusismo profesional, abrieron estos cambios. El gran salto adelante vino cuando las Cortes del Bienio Progresista aprobaron, el 28 de noviembre de 1855, la Instrucción General de Sanidad que, con algunas modificaciones posteriores, constituiría el corpus legal básico de la sanidad española hasta principios del siglo XX, cuando los Reales Decretos de 14 de julio de 1903 y 12 de enero de 1904 cubrieron la necesidad de actualizar el gran número de disposiciones aparecidas hasta entonces ${ }^{6}$.

Así como los grandes cambios en el ramo sanitario no se produjeron hasta que el nuevo marco liberal estuvo bien asentado, el sistema benéfico del Antiguo Régimen se vio profundamente afectado desde un buen principio por los trasiegos de las primeras décadas del siglo. Muy pronto, las medidas desamortizadoras de las Cortes de Cádiz decretaron que los ayuntamientos pasatían a encargarse de las casas de misericordia y otros establecimientos benéficos eclesiásticos, y que los de patronato particular, serían controlados por el Jefe políti$\mathrm{co}^{7}$. Este tipo de medidas fueron anuladas inmediatamente por la restauración absolutista posterior, pero los gobiernos liberales del Trienio las recuperaron y trazaron un plan de beneficencia bastante completo, de conformidad con lo

S Ley 30-6-1814 y Ley 23-2-1821 sobre salubridad en cementerios; Real Cédula 10-121828, regulando los Colegios de Medicina y Cirugía; i Real Decreto 20-1-1834 sobre policía e higiene de subsistencias en industrias y mataderos.

6 Esca ley es la base, pero fue reformada posteriormente por las leyes de 24-5-1866 y 29-61898. Posteriormente, la Instrucción General de Sanidad, de 12-1-1904, aprobada como Real Decreto, acabaría derogando finalmente la legislación decimonónica. Pero al margen de estas hubo otras disposiciones y proyectos de ley que reflejan la necesidad de reformar a menudo el texto base. Así, por ejemplo, cabe destacar los proyectos aprobados por el Consejo de Sanidad de 17-11-1857 y 2-12-1862. Dutante la Restauración, desde los años ochenta, se fueron presentando periódicamente varios proyectos de ley a los parlamentos, con mucho trámite, pero poco éxito. En febrero de 1881 se presentaron unas bases que sirvieron de fundamento al proyecto de ley de sanidad presentado por el Gobierno al Senado el 20 de marzo de 1882 , aprobado con varias enmiendas, en enero del año próximo, pero que nunca pasó del status de proyecto de ley de bases. También el proyecto presentado al Consejo en octubre de 1892 y el de ley de bases para una nueva ley de 18 de junio de 1894 . El único fruto de este proceso fue la Real Orden 16-3-1899, que encargaba al Consejo de Sanidad la redacción de las bases para una nueva ley, punco de origen de la instrucción que sería aprobada en 1904, aunque no en forma de ley sino de Real Decrero y, por lo tanto, sin el consiguiente trámite parlamentario previo, cosa que pone en evidencia las dificultades para llegar a un consenso y la forma de actuar de escos gobiernos.

7 Constitución de 1812, Arcículo 321. 
que el pensamiento liberal disponía en aquella época ${ }^{8}$. Sobre la base de la autonomía del municipio y la provincia, estableciendo en cada Ayuntamiento una Junta Municipal de Beneficencia, encargada de inspeccionar centros caritativos (Casas de maternidad, de socorros, hospitales para enfermos, convalecientes y locos, hospitalidad y socorros domiciliarios, etc.), se trataba de una legislación con dos grandes ejes, bastante diferentes, sino contrarios, a los que caracterizarían la de la segunda mitad de siglo: descentralización del modelo asistencial y priorización de la asistencia pública sobre la privada (fuerte control sobre los establecimientos particulares y, en muchos casos, absorción de estos por parte de la beneficencia pública). Igual como pasó en 1814, en 1824 se restauró todo lo que la tempestad liberal había derrumbado. El Real Decreto de 20 de abril de 1824 restableció las «obras de piedad de nuestros antepasados» $\mathrm{y}$, aunque se ha dicho que poco antes de morir Fernando VII ya se avanzaba hacia la reordenación del ramo de acuerdo con los principios del Trienio, lo cierto es que hasta el Real Decreto de 8 de setiembre de 1836 no se restableció la ley de 1822, que homogeneizaba y aseguraba el control público sobre los centros benéficos; y que eso duró muy poco, porque la Real Orden de 30 de noviembre de 1838 restableció rápidamente el respeto a la propiedad privada de los establecimientos particulares de beneficencia".

Un estudio en profundidad de estas cuestiones nos permitiría captar la evolución del pensamiento y la acción liberal en las décadas que configuraron el nuevo Estado. Ahora no nos podemos plantear un trabajo de estas dimensiones, pero sí un examen-valoración de la acción emprendida en los años centrales del siglo, sobre todo de la legislación surgida a partir de la Década Moderada, porque tuvo la continuidad suficiente para constituir el cuerpo legal básico desde entonces hasta principios del siglo XX: la corta Ley de 20 de junio de 1849 y el minucioso Reglamento de 14 de mayo de 1852 , referentes a beneficencia, y la Ley de 28 de noviembre de 1855 , sobre sanidad ${ }^{10}$. El examen de

Ley 10-10-1820, que prohibía a los establecimientos benéficos la posesión de todo tipo de bienes raíces. Decreto de Cortes de 21-12-1821, Ley 23-1-1822 y Ley 6-2-1822.

9 En este sentido, no parece acertado el planteamiento de Demetrio CASTRO ALFiN: Las necesidades sociales y su cobertura: 1800-1868, in Historia de la acción social pública en España. Beneficencia y previsión, Ministerio de Trabajo y Seguridad Social, Madrid, 1990. Al valorar el R.D. 16-7-1833 como un tímido avance de la monarquía absoluta hacia los principios liberales, el autor, a mi modo de ver, cae en el error de confundir la reorganización del ramo de acuerdo con una descentralización similar a la del Trienio con la asunción, aunque tímida, de los principios liberales. en ningún caso, por ejemplo, se habla en este decrezo de homogeneización, expropiación o intervención gubernativa en las fundaciones particulares, como había pasado entonces.

10 Esta continuidad en el riempo de la legislación elaborada entonces no es tan clara en beneficencia como en sanidad. Al margen de las vicisitudes del debace parlamentario, que obligaron a elaborar y reelaborar la ley varias veces, habría que tener en cuenta las varias disposiciones y decretos, en muchos casos poco explícitos, que modificaron a lo largo del siglo muchos de sus principios. Sobre todo, cabe destacar el Decreto 22-4-1873, de la Primera República, sobre establecimientos generales de Beneficencia, el Real Decreto de 27-4-1875, reestructurando el protectorado e ins- 
los puntos más significativos de lo que se teguló entonces nos ayudará a entender las limitaciones que el liberalismo español señaló de entrada en la gestión de unos aspectos con creciente importancia en el mundo industrial que estaba surgiendo"l.

\section{EL SISTEMA BENÉFICO EN EL NUEVO MARCO LIBERAL}

La ley de 1849 y el Reglamento de 1852 fueron el resultado de un largo proceso iniciado con las primeras reformas liberales, que tendían a reivindicar la titularidad pública de todos los centros benéficos. En las disposiciones de 1849 y 1852 , en cambio, ya sólo se estipulaba que los establecimientos benéficos serían considerados públicos cuando no fueran financiados exclusivamente con fondos propios, donados o legados por particulares, y cuya dirección y administración corriese a cargo de corporaciones autorizadas por el Gobierno o de patronos designados por el fundador ${ }^{12}$. Por otro lado, se consolidó la organización territorial jerárquica que perduraría por muchos años en la beneficencia española. La dirección se atribuyó al Gobierno, auxiliado por una Junta General establecida en Madrid, unas juntas provinciales, en cada capital de provincia $y$, en los pueblos, juntas municipales ${ }^{13}$.

pección que el Gobierno puede ejercer sobre los establecimientos de beneficencia particular, el Real Decreto y la Real Orden 27-1-1885, sobre orden interno en los hospitales de incurables y sobre régimen, gobierno y administración superior de los establecimientos de beneficencia general. Igualmente cabria prestar arención a las diferentes disposiciones que a lo largo del siglo fueron cambiando el status y el funcionamiento de juntas de beneficencia y entidades similates.

1 No existe bibliografía actual que trate el tema en toda su amplitud, por lo que hay que seguir recurriendo al trabajo de GRANJEL, Luis S.: Legislación sanitaria española del siglo XIX, in «Cuadernos de Historia de la Medicina Españolaw, Vol XI, 1972. Por lo que respecta a documentación básica, los textos de las principales disposiciones son fácilmente consultables en varios lugares. Son muy útiles las diferentes ediciones de MARTÍNEZ ALCUBILLA, Marcelo: Diccionario de la administración española. Compilación de legislación española en todos los ramos de la administración pablica, Madrid (Las ediciones consultadas son de 1892 y 1914). También son interesantes como introducción a estos temas varios artículos de la Encidopedia llustrada lbenamericana Espasa, Madrid-Barcelona, Espasa Calpe. De todas formas, es indispensable seguir los debates parlamentarios que llevaron a la elaboración de escos textos, principalmente en las legislaturas de 1849 y $1854-56$ en el Diario de Seriones de las Cortes (DSC), para tener una idea de las diferentes opciones que se barajaban entorno a escas cuestiones.

12 Este punto fue objeto de viva polémica a to largo del siglo. Sobre la discusión que generó en el debate parlamentario de 1849 , vid. DSC, 1849, p. 551 y ss.

13 Esta organización iba a cambiar varias veces a lo largo del siglo. Así, por ejemplo, poco después de la Revolución de septiembre, el Decreto Ley de 4 de noviembre de 1868 substituyó la Junta General, y hasta el 1908 no se creatía una Junta Superior que substituyese la anterior. Las facultades de las juntas provinciales y municipales, creadas en 1849 pasaron casi por completo a diputaciones y ayuntamientos como consecuencia del Decreto ley de 17 de diciembre de 1868 . La celeridad con que se respondía en este aspecto a cada cambio político lleva a pensar que la organización, funciones y composición de las juntas eran temas mayores que habría que investigar a fondo.

Hippania, LX/2, núm, 205 (2000) 597-622 
Los objetivos del corto proyecto presentado por el conde de San Luis (Sartorius), ministro de la Gobernación, el 15 de enero de 1849 eran muy explícitos: se trataba de reconducir el ramo hacia los principios de centralización que inspiraban las nuevas leyes de ayuntamientos y diputaciones, porque hasta ahora se venía regulando aún con las disposiciones de la ley del Trienio, restablecida el 8 de septiembre de 1836. Era preciso revisar esta ley, se dijo, porque, como producto de la Constitución de 1812 , respondía a criterios contrarios a los de la nueva Constitución de 1845 en materia de organización administrativa. A ello contribuían, según el ministro, la necesidad de poner orden al caos y a la depauperación producida por la despreocupación de los muchos patronos de establecimientos particulares que se habían desentendido de los objetivos de los fundadores de los centros que regentaban. Debido a eso se pretendía dotar al Estado de mecanismos de inspección y control sobre estos centros. Además, el Gobierno se reservaba el derecho a crear y suprimir establecimientos y a agregat y segregar sus rentas en todo o en parte (previa consulta al Consejo Real, ayuntamientos y diputaciones implicadas) ${ }^{14}$.

Se trataba de una disposición breve pero muy explícita, que pretendía alterar muchas cosas. No por casualidad suscitó bastante polémica en el Parlamento. La principal de las enmiendas a la totalidad que se presentaton fue la de un grupo de diputados encabezado por Fermín Gonzalo Morón ${ }^{15}$. Aunque Morón fuera uno de los hombres que posteriormente se sumaría decididamente al pro-

14 Proyecto de ley presentado al Congreso el 15-1-1849 (DSC, 1849, pp. 221-222), Art. 5

is En concreto, al margen del citado Gonzalo Morón, se trataba de Cristóbal Campoy Navarro, Bautista de Córdoba, el marqués de Montecastro, Diego Marín Barnuevo, José Polo y Perrández. Gonzalo Morón fue redactor y director de la «Revista de España y del extranjero» (1845), "La Epoca” (1850), «El trono y la Constitución» (1853), «La Verdad" (1853), «El León eppañol» (1855) y «El Ateneo de Madrid" (1859), en Madrid, y de aEl Turias (1853) en Valencia. (Vid. Ossorio Y BeRNARD, Manuel: Ensayo de un catálogo de periodistas españoles del siglo XIX, 1903). Ferdinand de Lesseps, embajador francés en Madrid, dijo de él en su famoso informe de 1848 que «...Acaba de ponerse en la oposición moderada, al lado de González Bravo y de Rios Rosas." (Vid. Moliner PRADA, Antonio (Ed.): Lesseps y los politicos españoles (El informe de 1848), Alicante, Diputación de Alicante, 1993). De B. de Córdoba y Miquel hemos sabido que venía de una de las mejores familias de Tortosa y que había escrito, entre ocras obras, estudios biográficos del jefe carlista Ramón Cabrera, de Jaime Balmes y de San Vicente Ferrer, todos ellos laudatorios hacia sus biografiados (Vid. SABATER, Sinesio: Album biográfico dertosense, Vol. I, 1892). Por orro lado, Sánchez Silva (Vid. SÁNCHEz Silva, U.: Semblanzas de los 340 Diputados a Cortes que ban figurado en la legislatura de 1849 a 1850, 1850) explica que Cristóbal Campoy «... fue auditor de guerra en el ejército de don Carlos, y cuando algunos intolerantes le dirigieron por ello alguna peladilla, no tuvo reparo en asegurar que era al gobierno de las moderados el más convenjente al pats, y que al jurar la constitución renunció a sus antiguas creencias y abjutó completamente sus errores.», y que José Polo era, también en 1849, «...uno de los jefes de la oposición conservadora". Aunque años más tarde, en 1853, encontramos a Gonzalo Morón entre los diputados moderados que intentaron una alianza con progresistas «de orden» como posible salida al vitaje ultraconservador que vivía por entonces la política española, los demás diputados identificados de este grupo pertenecían claramente al ala conservadora del Parlamento (Vid. BORREGo, Andrés: Estudios políticas de la onganización de los partidos en España, Madrid, Santa Coloma, 1855, pp. 122-123) 
yecto de un tercer partido liberal de centro que pudiera derrumbar al gobierno Sartorius, el carácter de esta enmienda era claramente conservador, reivindicativo de los derechos particulares, de la recristianización del ramo y de la no intervención gubernamental en asuntos benéficos. Gonzalo Morón lo argumentaba en un largo pero expresivo discurso:

«La legislación que hoy existe (...) producto de sistemas enteramente diferentes y opuestos sobre la administración de este país, puede decirse que es una verdadera anarquía. (...) Pero el proyecto que nos ha presentado el Gobierno, $\measuredangle(. .$.$) va a remediar (...) el estado verdaderamente lamentable en que se en-$ cuentran hoy en España los establecimientos de piedad? (...). Han visto la cuestión de una manera muy incompleta (...). La Comisión, señores, no ha visto más que una sola causa: la independencia de las Juntas, la independencia de los Ayuntamientos, la independencia de los patronos, en los cuales dicen los dignos individuos de la comisión que dominan los intereses privados, intereses que yo llamaré ilegítimos, porque esta es su verdadera calificación. (...) Y, senores, ¿es esto tan exacto (...) como la comisión lo dice? (...) La verdadera causa, señores, es necesario decirlo por más que nos sea doloroso a las personas que profesamos ciertas doctrinas, (...) son las leyes revolucionarias (...) que abolieron los diezmos, que hicieron imposibles las grandes pensiones de las mitras, y buscadlas sobre todo en ese principio exclusivo y tiránico de la desamortización, que priv6 a los establecimientos de beneficencia como a las manos muertas de aquellos grandes recursos con que se habían sostenido siempre. (...) Yo comprendo que se hablara mucho contra la amortización eclesiástica, aun en muestros días, cuando existían no a centenares, sino a millares, los conventos (...) pero lo que yo no comprendo (...) es la exageración que se está dando aun hoy a este principio.(...) Precisamente el cargo que le hago a la Comisión es ese: que no habla ni deja de hablar en punto a la amortización o a la desamortización, y como yo he manifestado que el principal recurso de los establecimientos de piedad es la adquisición de bienes raíces, califico de malo y de incompleto el proyecto de la Comisión, porque no fija este principio de una manera más explícita todavía que la que está consignada en las leyes de $1845{ }^{\prime 16 .}$

El caos financiero y los problemas derivados de las «leyes revolucionarias" eran uno de los aspectos fundamentales de las críticas de este grupo de diputados. Los problemas, a su modo de ver, se solucionarían si el Gobierno dejase de frenar la iniciativa de los cristianos, porque «...el recurso fundamental de los establecimientos de piedad está en la caridad de los fieles; está en la facilidad de adquirir bienes raícesm ${ }^{17}$, cuestión que conectaba la crítica fundamental, testricciones a la autonomía económica de los centros benéficos, con los otros dos grandes argumentos: centralización excesiva y laicización del ramo:

16 DSC, 1849, pp. 686-698.

17 DSC, 1849, p. 695. 
«¿En virtud de que principio, no sólo concedéis el nombramiento de esas corporaciones y de esos individuos, sino que limitáis a una sola puramente nominal la autoridad del presidente, el alcalde, haciendo que el vicepresidente sea nombrado por el jefe político, y dando con esto ocasión y motivo a que, o la autoridad del presidente no sea nada (...) o que haya continuas disputas entre el presidente y el vicepresidente, pues siendo este nombrado por el jefe político, no se creerá superior a aquel? (...) Los jefes políticos se ven rodeados exclusivamente de hombres políticos o de especuladores políticos. Aquellos hombres, señores, que hay oscuros en todas las poblaciones. Aquellos hombres que verdaderamente conocen las necesidades de los pueblos, a los cuales pudiera confiarse con acierto la dirección de los establecimientos de piedad, esos hombres generalmente no los conocen los jefes políticos 18 .

«...la comisión (...) ha secularizado completamente la beneficencia pública, y en esta parte el proyecto de ley presentado por el Gobierno moderado es más pagano, permítaseme la expresión, que la ley del año 22 (...) que ha sido perjudicialísima a los establecimientos de piedad, pues en el momento que se ha puesto en ejecución ha sido la señal de decadencia y de ruina de los establecimientos de piedad: esa ley que destruyó de un golpe la organización especial que tenían los establecimientos de piedad en España: esa ley que estableció esos cuerpos llamados Juntas municipales, cuya organización no es ni puede ser conveniente a los establecimientos de piedad (...) esa ley que atacó la dotación de esos establecimientos acordando la centralización de fondos (...) esa ley con todos sus defectos ha hecho cuando menos cierta justicia, ha dado importancia al espíritu religioso y a la influencia del clero. Esa ley ha consignado que los curas-pátrocos debían ser necesatiamente individuos de las Juntas municipales?»19.

Los miembros de la comisión respondieron negando todas las acusaciones. El diputado Vahey, después de defender la actitud desamortizadora, negó que el proyecto estipulara la prohibición de amortizar y adquirir bienes. Si la legislación de 1822, retomada en 1836, así lo establecía, dijo, el Gobierno no la entendía vigente, porque las disposiciones aparecidas a partir de 1845 lo contradecían. Asimismo combatió la presunta laicización del ramo de beneficencia. Pero la problemática al entorno de las funciones, poderes y composición de las juntas fue, sin duda alguna, el punto de mayor fricción entre las dos opciones. Para Morón, el intento de organizar el ramo a partir de juntas con carácter territorial chocaba con el espíritu particular que debía tener la beneficencia: en su opinión, cada establecimiento debía tener una junta particular de caridad, presidida por un eclesiástico y constituida por los patronos del centro y algún representante del vecindario pudiente. El intento de regir estos establecimientos desde juntas de base local respondía sólo al interés de la administración en ejercer una "centralización excesiva», en controlar unos establecimientos que, por definición, tenían que ser autónomos; y mucho más aún si la designación de estas juntas

18 DSC, 1849 , p. 697.

19 DSC, 1849 , p. 698 . 
locales no se delegaba en «vecinos pudientes y cristianísimos» del pueblo sino en el Jefe político. La respuesta de Esteban Collantes, en nombre de la comisión redactora del Gobierno, puso en evidencia la distancia entre ambas visiones:

\begin{abstract}
«La beneficencia pública en España en los antiguos tiempos, en los tiempos en que era dirigida casi exclusivamente por el clero (...) hacian de la beneficencia más una cosa de lujo que caritativa, estos establecimientos han estado muy mal dirigidos. En los tiempos posteriores, en tiempo de la guerra y de la revolución, la beneficencia pública no ha adelantado cosa mayor, pero ha tomado un carácter particular, el carácter que nosotros pretendemos darle por completo en el proyecto de ley que se está discutiendo (...), que consiste en dar al Gobierno sobre estos establecimientos toda la inspección necesaria, pero dejando a salvo las atribuciones propias y exclusivas de los Ayuntamientos para vigilar de cerca e intervenir directamente en las operaciones peculiares de estos establecimientos. Es, por consiguiente, completamente equivocada la idea que aquí se ha emitido de que en este proyecto se ha admitido la parte administrativa que le corresponde de la manera más exageradamente centralizadora. (...) Es una verdad reconocida por todos que los bienes de la beneficencia se han vendido mal, los que se han vendido; (...) que los que están arrendados, lejos de crecer en rentas, han disminuido, cuando los de los particulares en igual caso han subido muchas veces un 100 por 100 . (..) Pues estas cosas son las que necesitan remedio (...). Y, señores, téngase presente que a los establecimientos de beneficencia, no tanto hace falta dotatlos, como examinar previamente lo que ahora tienen, y para eso es para to que quiero yo la acción gubernativa del Gobierno, para que examine donde hay ocultaciones (...) ¿Cómo han de hacer eso los pueblos ni los Ayuntamientos, si son quizás los más interesados en estas ocultaciones, porque se están aprovechando de sus bienes? (..) Lo que aquí se oye a todo el mundo que se ocupa de estos negocios es que el Gobierno tiene poca vida propia, poca vida administrativa en el régimen de los pueblos, que lo que aquí hace falta es que los jefes políticos sean las únicas y exclusivas autoridades que haya en los pueblos. Y distamos mucho de eso, señores, para quejarnos de un exceso de centralización: yo me quejo de lo contrario... ${ }^{20}$.
\end{abstract}

Aunque extensos, estos discursos revelan cuales eran los argumentos y los intereses de ambas fracciones del partido moderado en un debate que resultó larguísimo y que aquí no podemos analizar a fondo. Al margen de establecer los puntos centrales del debate, interesa remarcar que esta enmienda fue rechazada por el Pleno, pero que, de todas formas, una vez en el Senado, el proyecto vio cambiados muchos de sus artículos y su sentido general. En una clara muestra del sentido político de la bicameralidad, la comisión mixta SenadoCongreso, presidida por el Arzobispo de Toledo, preservó la mayoría de los aspectos introducidos en el Senado y que desvirtuaban claramente los aspectos más intervencionistas del proyecto inicialmente presentado. Así por ejemplo, el artículo primero, que en un principio restringía casi totalmente la pervivencia

20 DSC, 1849, p. 726-730

Hispania, LX/2, núm. 205 (2000) 597-622 
de establecimientos particulares, ahora los contemplaba en muchos aspectos ${ }^{21}$. Por otro lado, aunque se acabase aceptando el criterio de territorialidad en la organización de las juntas (generales, provinciales y municipales), en vez de establecer una en cada centro, como pretendían los defensores de la enmienda que se rechazó, estos no podían mostrarse descontentos, porque la ley acabó estipulando detalladamente las funciones y la composición de cada junta en unos términos muy afines a sus criterios. Al margen de la omnipresencia de eclesiásticos, se previó la presencia de los patronos de los principales centros benéficos de cada pueblo, en detrimento, a menudo, de la representación del poder político. De esta forma, la centralización y el intervencionismo buscados por el Gobierno se vieron en buena medida frustrados por esta presencia de dirigentes de los establecimientos en unas juntas que en principio se habían pensado como control a los mismos.

La suerte que, indirectamente, tuvo esta enmienda no la compartió otra de las presentadas. El conocido periodista y político Andrés Borrego (importante puntal del liberalismo durante el Trienio y, posteriormente, del monarquismo progresista durante el Sexenio, situado en esta época en el ala izquierda del partido moderado, insistiendo en sus repetidos intentos de unión liberal por el centro) salió en defensa de la obligatoriedad de la beneficencia, influenciado, seguramente, por sus conocimientos sobre la vida política y administrativa inglesa ${ }^{22}$. Lo hizo argumentando que no proyectaba nada nuevo, sino basándose en unas disposiciones que no tan sólo no habían sido derogadas sino que, al menos en teoría, ahora se pretendía reformar sólo en su parte administrativa y no en su espíritu:

21 En este sentido, uno de los puntos más reivindicados por los autores de la enmienda era eliminar una cláusula que escipulaba que, una vez muerto quien, por tazón de su cargo u oficio, ejercía el partonazgo de un establecimiento, esta potestad pasaba al Estado y no a sus herederos. Este punto era especialmente reivindicado desde instancias eclesiásticas en la medida que muchos clérigos regentaban, en virtud de su posición, establecimientos de beneficencia de orden muy variado. Aunque en el Congreso esta cláusula se mantuvo, en el Senado se cambió completamente.

22 Cabe tener en cuenta que en esta época, y durante todo el siglo XIX, Inglaterra era vista por un amplio sector del liberalismo moderado español como el pás de a llamada «beneficencia legals, aquella que se basaba en el criterio de obligatoriedad de la asistencia a los pobres desde el poder público, de efectos altamente perniciosos en su opinión. En este sentido, la opción de Borrego eta muy minoritatia en las filas moderadas. (Vid. SÁNCHEZ SIlvA, U.: Op. cit.: "Todas las ideas que ba entitido el señor Borrego acerca de la administración revelan el estudio que ba becbo del sistema ingles, en cuyo país ba permanecido mucho tiempo.m. También Ossoruo Y BERNARD, M: Op. cit.; OVILO Y OTERO, M.: Manual de biografía y de Bibliografía de los Escritores españoles, 1859). Otros diputados acompañaron a Borrego en la presentación de esta enmienda, auque fuese el único que la defendió en el Parlamento. Se trataba del marqués de Montecastro (curiosamente, también firmó la enmienda del grupo de Gonzalo Morón), José Pardo Montenegro, Antonio Benavides, Careaga y Ramírez, Ferrández y Manuel Merelo y Calvo. Sobre Borrego existe una bibliografia relativamence amplia, aunque poco actualizada. Una recopilación de los trabajos del políico conservador y estudios sobre su figura en CASTRO, Concepción de: Andrés Borrego. Periodismo liberal conservador (1830-1846), Madrid, Miguel Castellote, 1972. 
«...esa ley de las Cortes del año 1822 (...) dejando enteramente aparte todo lo concerniente a la manera y al modo de administrar estos establecimientos y a la forma con que deben ser regidos, esa ley, señores (...) es una verdadera ley de beneficencia, porque consagra el principio de la obligación que el Estado tiene a atender a las clases menesterosas... $\rangle^{23}$.

Los principios de esta ley aparecían en la Constitución de 1812, y también posteriormente en unas Cortes reunidas después de promulgada la Constitución de 1837, así como en sendos proyectos de ley de beneficencia, «...presentados por gobiernos moderados a cortes también moderadas", en 1837 y 1838 . Como acababa de demostrar, su enmienda estaba «...en el espiritu de la legishación actual»; y por lo tanto era preciso que el proyecto explicitase en qué estado quedaban estos términos de la legislación anterior. Pero según el ministro de la Gobernación (conde de San Luis), la enmienda, además de innecesaria, era peligrosa:

«...que la beneficencia pública es un objeto a que debe atender el Estado, el Gobierno, es una verdad harto conocida, una verdad innegable; pero una cosa es eso y otra cosa es consignar en la ley el principio. El principio se ha de consignar para algo y desde el momento que se consigna, lo esplotan, señores, los trastornadores de las masas; y de uno en otro paso se viene a parar en lo que han parado las cosas en Parísw ${ }^{24}$.

Borrego insistió, aclatando que no lo movían ideas anárquicas ni socializantes, sino conservadoras, refiriéndose constantemente a lo que estaba pasando en Francia e Inglaterra en aquellos agitados años, y pidiendo al Gobierno que aclarase aquellos puntos de la ley como única forma de evitar estos desórdenes 25. Aunque las explicaciones del ministro fueron satisfactorias y aceptó retirat su enmienda, más adelante insistió de nuevo. En la discusión de los artículos décimo y quinceavo, sobre los derechos del Estado en la agregación y supresión de centros benéficos, aprovechó para llamar la atención sobre el silencio de la ley en materia de obligaciones del Estado, sobre todo al no estipular la obligación de proporcionar recursos a los establecimientos peor dotados. Esteban Collantes lo desmintió y, al insistir Borrego, el ministro de la Gobernación respondió de forma contundente:

«...o lo que pide que se consigne (...) es una cosa ridícula o es una cosa peligrosa: o es la recomendación de que todos los españoles sean justos y benéficos,

23 DSC, 1849 , p. 737.

24 DSC, 1849 , p. 738.

29 Reflexiones de Borrego sobre los hechos de 1848 así como de sus teotías sobre política preventiva de desviaciones tevolucionatias en BORREGo, Andrés: El 48. Autocritica del liberalismo. Comentado por D. Gómez Molleda, Madrid, Iter, 1970, especialmente el trabajo titulado sistema de reformas propio para asegurar todas las conquistas de la libertad, sin incurrir en ensayos revolucionarios". 
(...) o es la recomendación de un principio de socialismo que de ninguna manera puede el Gobierno admitir. (...) si lo que quiere es que se consigne aquí como una obligación, esto, además de imposible, es altamente peligroso, es querer el socialismo y el socialismo puro. (...) Claro es que siendo una obligación sagrada que no puede ningún Gobierno desconocer, no puede tener otra medida ni otro límite sino la posibilidad en aquello que el Gobierno pueda”26.

Borrego anunció que por el momento callaría, pero que se guardaba para la discusión del artículo final, sobre extinción de la mendicidad, un discurso sobre el pauperismo como problema crucial en el mundo que llegaba, donde pensaba volver a insistir sobre estos argumentos. Pero no pudo hacerlo porque, justo al entrar a discutir este artículo, la Comisión decidió retirarlo del proyecto. Visiblemente molesto, respondió que «...se ba retirado este artículo únicamente para privarme de dar al Congreso las explicaciones que me ballaba en el caso de darle después de lo que ocurrió en la sesión de ayern. La respuesta del ministro fue de nuevo contundente:

«...de ninguna manera puede tener el Gobierno la lucha de doctrinas en este Parlamento, mucho menos la cuestión que ayer promovió el señor Borrego.» 27

Dicho esto, quedó cerrada la cuestión y el proyecto quedo visto para pasar al Senado. Se había abortado sin demasiados problemas la pretensión de Borrego. Por otro lado, la enmienda del grupo de Gonzalo Morón, que había sido frenada en el Congreso, reviviría en el espíritu de las reformas que impondría el Senado. Se acabó aprobando una ley que regiría durante muchas décadas y que enmarcaría la beneficencia española dentro de unos límites muy claros; una ley que desvirtuaba visiblemente el moderado proyecto inicial.

Es importante retener la contundencia del debate para remarcar hasta que punto nos equivocaríamos si pensásemos que el discurso liberal era homogéneo en materia asistencial. El papel que la desigualdad social adquiriría en el nuevo mundo no era, ni mucho menos, conocido, valorado y asumido de igual forma por todos. Incluso entre la inmensa mayoría de políticos liberales que, como Borrego y el ministro Sartorius, en aquellos momentos ya entendían como natural e inmutable la desigualdad entre ricos y pobres, había concepciones bastante diferentes sobre como había que hacer frente a esta situación en la sociedad que se estaba configurando. El análisis comparativo de los distintos proyectos legislativos de la primera mitad del siglo, al margen de su efectividad práctica, nos ayuda a captar la complejidad y la evolución del pensamiento liberal, así como conocer el marco y las limitaciones que condicionaron la asistencia pública en las décadas posteriores. La ley de 1849 , desde esta óptica,

26 DSC, 1849 , p. 851.

${ }_{27}$ DSC, 1849 , p. 868. 
supuso claramente un giro frente a las tendencias laicizadoras y centralizantes que un cierto liberalismo pretendía imponer en los años veinte y treinta ${ }^{28}$.

\section{LA ACCIÓN PÚBLICA EN MATERIA DE SANIDAD}

La actuación sanitaria se dividía en tres grandes aspectos: organización y administración general, polića sanitaria interior y policía sanitaria exterior. El primero comprende tanto aquellas instituciones con funciones consultivas (Real Consejo de Sanidad, Juntas provinciales y municipales) como inspectoras (Subdelegados e Inspectores generales, provinciales y municipales) como los profesionales propiamente dichos (colegios y jurados profesionales, facultativos, brigadas sanitarias, etc.). Como policía interior se entendía toda la organización destinada a controlar y fomentar la salud pública a nivel interior del reino, sea en el campo o en la ciudad: control alimenticio, de medicamentos, de aguas minerales, de cementerios, de enfermedades contagiosas, etc. Una acción destinada sobre todo a prevenir el contagio epidémico, la gran preocupación del momento. El avance de la industria y del comercio y las dolorosas experiencias de los contagios recientes (no podemos olvidar la epidemia de cólera de 1854, justo un año antes de la promulgación de esta ley) eran los dos elementos centrales a cuyo entorno giraba la preocupación sanitaria29. Desde esta perspectiva, se entiende que el aspecto más completo en el tratamiento legislativo fuera el régimen sanitario exterior: el control del comercio internacional y de la salubridad de los puertos serían fundamentales en un mundo en que el extraordi-

28 Esta visión no concuerda con la de CASTRO ALFín (Op. cit., pp. 91-97), al juzgar la ley de 1849 especialmente desde sus aspectos centralizadores e intervencionistas. Si la comparamos no sólo con los proyectos de las décadas anteriores sino también con el que se presentó en un principio en 1849 nos daremos cuenta de hasta qué punto la ley aprobada desvirtuaba estos aspectos. Que esta es la visión correcta lo cotroboran, en mi opinión, unas explícitas palabras de Romero Robledo al presentar, el 27 de abril de 1875, un Real Decreto que acentuatía aún más los aspectos privatizadores de la beneficencia española. Al repasar las disposiciones anteriores, el político conservador decía que «...cuando la lógica de los principios gabermantes pareda pedir todo género de respetos para la acción individual y para las instituciones particulares, se lanzaron contra las beneficas los más rudos ataques; y la ley de 23 de emero de 1822, fruto de una preocupación exagerada en pro de la organización autonónica del Municipio y de la provincia, les sacrificó toda creaction particular. Por el contrario, cuando más pujante parecta, por natwral reacción, el espiritw centralizador, abtuvo la Beneficencia particular mayores respetas en la ley de 20 de junio de 1849 .

29 En la presentación a las Cortes que Francisco Santa Cruz, ministro de la Gobernación, hizo del proyecto de ley de sanidad era evidente la centralidad de esta doble preocupación, sobre todo en lo que respecta a la rigidez que, por el ritmo y la importancia del comercio moderno tenían los sistemas cuarentenarios de estilo antiguo: «No pueden sostenerse con el progreso que el comercio y la industria ban adquirido en los altimos años, auxiliados por las ciencias naturales, sin perjudicar gravemente sus intereses, las largas cuarentenas que nuestra actual legislación sanitaria prescribe (...). Las lecciones que la altima invasión de colera-morbo nos ba dado, dejaron conocer bien los inconvenientes que consigo lleva el rigor de las medidas coencitivas, o más bien su excesiva prolongación." 
nario avance de las relaciones comerciales internacionales puso de manifiesto la amenaza creciente del contagio epidémico. Aunque ahora obviaremos este aspecto y nos centraremos solo en la política sanitaria interior, no podíamos dejar de citar al tema que más debate generó y de cuya importancia e interés no podemos dudar.

Siguiendo el modelo tradicional de la sanidad y de tantos otros ramos de la administración española, se estableció un sistema organizativo a tres niveles: estatal, provincial y municipal, basado en las juntas de cada pueblo y cada provincia, que siguieron las directrices emanadas desde la Dirección General de Sanidad, y del órgano central de esta, el Consejo de Sanidad, dependientes del Ministerio de Gobernación. Se pretendía que esta Dirección General sustituyese a la Junta Suprema de Sanidad vigente hasta 1847 y muy criticada por los gobernantes progresistas. No estamos en condiciones de valorar en su conjunto la institución de las juntas, pero sí cabe que alertemos del error que supondría creer que, bajo un único nombre, no se escondían composiciones y formas de funcionamiento muy diferentes a lo largo de los años. No puede ser casual que cada vez que había cambio de tendencia política en el Gobierno la supresión de las juntas de estilo antiguo y la instauración de otras de nuevo cuño fuese una de las primeras acciones que se emprendieran. En este sentido, es significativo que los gobiernos progresistas del Bienio retomaran la iniciativa que en 184647 habían tenido gobiernos moderados de signo puritano (el ala izquierda del moderantismo). El intervencionismo que suponía este tipo de acciones había sido rechazado por los gobiernos moderados anteriores, cuando Mateo Seoane (uno de los médicos más influyentes en la configuración del régimen legal de la sanidad liberal española) había presentado proyectos de ley en este sentido ${ }^{30}$

Las diferentes opciones sobre quien debía componer estas juntas y sobre el tipo de funciones que habían de tener eran los dos temas de debate constante. En este sentido, por ejemplo, sería interesante estudiar la evolución de los proyectos que Mateo Seoane, entre otros, elaboró, entre 1822 y la definitiva adopción de la ley de 1855 . El primer proyecto, de 1822, del que Seoane fue el principal impulsor, preveía una Dirección General muy diferente, tanto de las entidades análogas previas como de las que se acabarían formalizando más adelante. Tenía previsto que fuera formada por tres vocales (profesionales y remunerados): dos médicos y un «individuo inteligente en los ramos de navegación y economía política", y precisaba cuales serían sus funciones, no limitadas, ni mucho

30 R.D. 17-3-1847, que suprimía la Junta Suprema de Sanidad. Sobre la política y la composición de los partidos en esta época, hay que consultar CÁNOVAS SÁNCHEZ, F.: Los partidos políticos, in Historia de España, dirigida por R. Menéndez Pidal, Vol. XXXIV, Madrid, Espasa Calpe, 1981. Sobre Mateo Seoane y los proyectos de sanidad que presentó, hay que ver el estudio y la recopilación de sus trabajos presentada por LÓPEZ PIN̄ERO, J.M.: Mateo Seaane. La intraducción en España del sistema sanitario liberal (1791-1870), Madrid, Ministerio de Sanidad y Consumo, 1984 
menos, a un mero papel consultivo ${ }^{31}$. Igualmente, estipulaba que en las juntas no podría haber representantes del comercio, por ser incompatibles sus intereses personales con la defensa de las necesidades reales del ramo. Las propuestas iniciales de Seoane se verían frustradas, no ya por el fracaso de aquel gobierno liberal de los años veinte, sino que ni tan siquiera sus proyectos posteriores irían en esa dirección ${ }^{32}$. Faltaría ver en qué modo las propuestas posteriores $(1838,1845,1846, \ldots)$ irían limitando progresivamente sus objetivos, en qué medida el que se aprobó en 1855 se vio influenciado por estos proyectos anteriores y hasta qué punto los desvirtuaba. Aunque se respetó la Dirección General y el Consejo como substitutivos de la Junta Suprema, la ley de 1855 los organizó con un grado de centralización mucho mayor y una composición muy diferente de la que en un principio había previsto Seoane. La Dirección General dejaba de estar formada por tres facultativos para recaer en una sola persona, dependiente del Ministerio, y auxiliada por un Consejo con funciones puramente consultivas (excepto en periodos especiales de epidemia). El Consejo sería presidido por el ministro de la Gobernación y la vicepresidencia quedaría en manos del «...que corresponda a las clases más elevadas de los empleados cesantes o jubilados en el ramo administrativo» (art. 4). Los demás miembros del Consejo, todos nombrados por el Rey a propuesta del ministro, serían el director general de sanidad, un agente diplomático, un jurisconsulto, dos agentes consulares, cinco profesores de la Facultad de Medicina, tres de la de Farmacia, un catedrático del Colegio de Veterinaria, un ingeniero civil y un profesor académico de arquitectura. Todos estos cargos serían honoríficos y gratuitos.

De acuerdo con los decretos de 1847 y 1848 , la nueva ley también regulaba el funcionamiento de las juntas provinciales y municipales que, en buena medida, venían a actuar de forma paralela al Consejo. Dispuso que todas las capitales de provincia tuvieran Junta provincial, y que todos los municipios con más de 1000 habitantes tuviesen Junta municipal. Las provinciales estarían compuestas por un presidente (el Gobernador civil o su representante), un vicepresidente (un diputado provincial), el alcalde de la capital de la provincia, el capitán del puerto (en caso de haberlo), un arquitecto o ingeniero civil, dos

31 Proyecto de Código Sanitario para la Monarquía Española (1822), Art. 11. Esta, como las demás referencias a este caso se han extraído de LóPEZ PIN̂ERO, J.M.: Op. cit.

32 Aunque el proyecto de ley de sanidad del Trienio no llegase a aprobarse, es interesante seguir los debates parlamentarios que generó en 1822. Mientras que en el proyecto parecia claro que el rarno se organizaria (a diferencia del de beneficencia) de forma profesionalizada y remunerada (Vid. DSC, 1822, p. 655 y ss.), un grupo importante de diputados, que acabó imponiendo su opinión en este asunto, argumentaba que «Los establecimientos de sanidad, según están creados en España y en todas las naciones cultas (...) no son establecimientos de bigiene ni de medicina (...) sino instituciones politicas, y muy políticas, para salvar la mayor riqueza de un Estado, que son los bombres. (...) ¿Cómo, pues, se ba de pretender organizar las Juntas de Sanidad de un modo tan cientifico y facultativo y con tales atribuciones (...) en que los Jefes Poltiticos, Rdos. Obispos, curas, alcaldes, diputados de provincia y regidores vendrian a ser miembros ad honorem o socios supernumeratios o meras oyentes...? (DSC, 1822, pp. 663-664. Voto parzicular firmado por los diputados Fraile, Espiga, Castanedo, Domínguez, Martel y Azaola). 
profesores de la Facultad de Medicina, dos de la de Farmacia y uno de la de Cirugía, un Veterinario y utres vecinos que representen la propiedad, el comercio y la industria». La composición de las juntas municipales se previó mucho más simple: las presidiría el alcalde y le acompañaría un médico, un farmacéutico, un cirujano (si había), un veterinario y tres vecinos.

Es importante que prestemos atención a la composición de estas juntas porque fue uno de los temas clave en la discusión parlamentaria de la ley de 1855. Ya en el preámbulo del proyecto que la originó, el ministro explicitaba que la tan celebrada institución del Consejo de Sanidad «...adolece (...) de defectos en su organización", porque "...es menester dar en él a las ciencias médicas la preferencia que la naturaleza misma de la institución reclama, dando al propio tiempo entrada a individuos de la carrera diplomática o consular, del comercio y la marina, a ingenieros $y$ arquitectos, como peritos en las transacciones mercantiles $y$ cuestiones internacionales $y$ en distintos ramos que influyen mucho en la sanidad de los pueblosw33. De aquí surgió la composición del nuevo Consejo tal como antes especificamos, y que no fue cuestionada por nadie en el Parlamento. El debate llegó al abordar temas más específicos sobre la sanidad en los pueblos y provincias. La composición que se proyectaba para las juntas municipales y provinciales fue enérgicamente contestada ${ }^{34}$.Los diputados Pérez Zamora y Bayarri fueron quienes más insistieron en esta cuestión ${ }^{35}$. Se pronunciaron contra «...la manera como se quiere en este artículo, así como en los demás de la ley, favorecer a la facultad de medicina, siendo asi que no se da gran participación en estas Juntas a la propiedad al comercio y a la industria". El representante de la comisión les replicó diciendo que «...cuando se trata de una ley de sanidad y se da la preferencia a las personas más competentes en la aplicación de esta misma ley, no sé porque ba de extrañarse». El problema, según Bayarri, era el poder que se daba a los médicos en unas juntas que tenían funciones que iban más allá de las estrictamente científicas ${ }^{36}$. En nombre de la comisión redactora del proyecto, respondió Calvo Asensio acaloradamente:

33 DSC, 29-3-1855, p. 3372

34 DSC, 8 a $21-6-1855$, pp. $5490-5840$

35 Feliciano Pérez Zamora, representante de la circunscripción de Tenerife, militante progresista desde los años cuarenta, se dio a conocer en la polírica madrileña durante el bienio 1854-56, en los bancos del partido progresista. Fue de los que posteriormente se sumó a la Unión Liberal, de O'Donnell. Durante el Sexenio defendió la Revolución desde el monarquismo y en la Restauración se colocó al lado de Cánovas. (Vid. Los diputados pintados por sus bechos, 1870; y TEBAR, P. E.- OLMEDO, J.: Las segundas Cortes de la Restauración, 1879). Pedro Bayarti, diputado por Castellón, también fue de los que se sumaron a Unión Liberal al final del Bienio. En 1856 y 1857 , y hasta su muerte, fue ministro de Marina con O'Donnell. (Vid. Baibas, Juan: Castellonenses ilustres, 1883). No deja de ser significativo que las críticas más duras a la presencia de científicos en las juntas viniese de hombres coicidentes en trayectoria política.

36 «Yo no diria eso si la Junta superior de sanidad no tuviera más atribuciones que las sanitarias, pero se Le dan ofras a las cuates anuncio desde abora que me opondré. (...) superando la influencia de una clase determinada, temo mucho por los intereses de los pueblos si llegan a enlazarse los intereses de esta clase en opasición a las intereves de la población (...) será muy bueno para cuando se srate de evitar un contagio o de tomar medidas 
«Las clases médicas (...) son las menos recompensadas, a pesar de sus continuos desvelos,(...). Parece que está pesando sobre ellas una especie de anatema, tanto más terrible cuanto mayores son los bienes que derraman. No parece sino que las clases médicas son las enemigas declaradas de la sociedad, y que por eso es preciso mirarlas siempre con esa odiosa prevención o con ese desdén inmerecidon ${ }^{37}$.

Ante la imposibilidad de llegar a un acuerdo, se procedió a la votación y se aprobó por mayoría la composición de las juntas de la forma que había proyectado la comisión. Esta vez, el Gobierno consiguió imponer una importante presencia científica en las juntas, contra la presión de un buen número de diputados que, desde las filas del propio partido progresista, apostaban por la continuidad de juntas formadas sobre todo por «fuerzas vivas".

Para nuestros objetivos nos interesa aún más otro aspecto del debate, en el que la discusión aún fue más dura, y en el que el Gobierno se vio obligado a retirar su propuesta. La comisión había presentado dos artículos redactados en los siguientes términos:

"Art. 74.- En todos los pueblos que sea posible, a juicio de las Juntas provinciales de sanidad, se establecerá la hospitalidad domiciliaria y se nombrarán por los Ayuntamientos médicos, cirujanos y farmacéuticos encargados de la asistencia médico-farmacéutica de las familias pobres; teniendo también los facultativos el deber de auxiliar con sus consejos científicos a los Municipios en cuanto diga relación con la policía sanitaria.

Art. 75.- Cuando un pueblo por su pobreza o escaso vecindario no pueda por si solo constituir partido suficiente para cubrir los honotarios de los profesores titulares, se asociará al efecto a los más inmediatos, acordando entre ellos, no solo la parte con que cada pueblo ha de contribuir para el pago de sus facultativos, sino el punto de residencia más conveniente de estos para utilidad de todos».

Aunque fuese sutilmente, este redactado implicaba la obligación de montar sistemas de asistencia domiciliaria y cuerpos médicos municipales relativamen-

\footnotetext{
para contener una epidemia; pero cuando se trata de que la Junta de sanidad decida los pkeblos en donde ba de baber médicos titulares y deba atender en la separación de facultativos, atribuciones que no concedo más que a las Dipustaciones provinciales, no puedo yo aprobar que tengamos una clase superior a las clases generales mwnicipales del Ettado..." (DSC, pp. 5840-5841).

37 Pedro Calvo Asensio, diputado por Valladolid, fue una de las voces destacadas del gobierno progresista durante el Bienio. Doctor en farmacia y derecho, ejerció sobre todo como periodista $(E l$ Restaurador farmacítitico, La lberia, El demócrata), literato y político. Una vez fracasada la experiencia del Bienio, se opuso firmemente a los gobiernos de Unión tiberal. (Vid. Ossorio Y BERNARD, M.: Ensayo de un catálogo de periodistas españoles del siglo XIX, 1903; y OLMEDILIA Y PUIG, J.: Bocetos de algwnas celebridades..., 1904). Sobre la evolución legal del status médico en la España del siglo XIX, aunque con aseveraciones dudosas en mi opinión, vid. ALBARRACIN TEULÓN, A.: Revolvción y medicina: una interpretación de la sardia ordenación de la asistencia médica en la España del sizlo XIX, in «Dynamis", Vol. 5-6, 1985-86
} 
te complejos. Fue este carácter compulsivo lo que motivó que un grupo de diputados presentase una enmienda donde mostrar su más radical desacuerdo ${ }^{38}$. Joaquín Alfonso defendió la enmienda porque el proyecto significaba, a su modo de ver, un abuso a la libertad y un escarnio a la autonomía de los municipios:

«...el Municipio debe tener cierta independencia; (...) debe atender a sus necesidades; (...). Hoy las atenciones del Municipio son las que están en España más desatendidas; pero las de los enfermos, no hay tal vez un solo Municipio en España que no las atienda. Por consiguiente, los señores de la Comisión no pueden alegar las razones de necesidad ni de precedentes que autoricen esa subversión (...) de los principios sobre los cuales debe estar consituido el Municipio. La Comisión quiere que por corporaciones extrañas al Municipio se organice la asistencia de los enfermos bajo un punto de vista que no siempre puede ser el del verdadero interés del Municipio...." ${ }^{39}$.

Calvo Asensio, al responder en nombre de la comisión, argumentó que Alfonso había ido demasiado lejos en su defensa de los principios liberales, porque «...si se dejara en completa libertad a los pueblos para proporcionar a los pobres los auxilios facultativos $y$ otros de indole análoga, de seguro que estas cargas se refundirian en cada uno de ellos entre cinco o seis personas bumanitarias que lo barian espontáneamente, y las demás se creerian dispensadas de toda obligación (...) si todas las personas tuvieran sentimientos bumanitarios y filantrópicos como el Sr. Alfonso, no babría necesidad de imponer obligaciones, mas por desgracia la sociedad necesita de todo esto, $y$ por eso se bacen las leyes.». Después de una serie de réplicas por parte de Alfonso, el ministro (Huelves), también salió en defensa del proyecto de la comisión:

«Su señotía sabe muy bien el afán de muchísimos pueblos (...) para que se les permita nombrar facultativos que asistan a las clases pobres, porque en muchos pueblos está abandonado, y dejarlo así como quiere el Sr. Alfonso, será como decir que las clases pobres no tienen asistencia de ninguna clase. (...) Esas sociedades de que ha hablado el Sr. Alfonso, son entre personas acomodadas (...) Pero el facultatitvo pagado del producto de esa suscripción no asiste nunca a ningún pobre, más que a los suscriptores (...); los pobres que no pueden pagar (...) se ven

\footnotetext{
38 Los diputados en cuestión fueron Joaquín Alfonso, Alvaro Gil Sanz, José C. Sorní, Cristóbal Valera, José María de Orense, Eduardo Ruíz Pons y José Ignacio Llorens. No pude idencificar claramente la tendencia política de Joaquín Alfonso, diputado por Valencia y redactor de «El Justicia» en aquella capiral, que fue quien habló en representación del grupo. De todas formas, la presencia de Sorní, Orense y Llorens, progresistas en el Bienio, dernócratas posteriormente y republicanos federales durante el Sexenio deja pocas dudas sobre la posición política del grupo en la izquierda del Parlamento. Si hay que hacer caso del sentido de esta enmienda, parece que en estos momentos el liberalismo más puro aún mantenía la libertad como valor primordial, aunque esto supusiese renunciar a la protección social que habría significado la obligatoriedad de una cobertura médica para el conjunto de la población.
}

39 DSC, 25-6-1855, p. 5952. 
completamente abandonados. Claro es que los Ayuntamientos y el Gobierno tienen el deber imperioso de asistir a los pobres con el alimento y el vestido en lo que puedan dar: no se trata directamente de mantenerlos y vestirlos, porque eso tiene cierta tendencia al socialismo; pero en fin, de proporcionar los recursos para que puedan mantenerse y vestirs ${ }^{40}$.

Lo más significativo de este caso es que la postura del Gobierno y de la comisión perdió la votación y se impuso claramente el criterio del grupo de Alfonso. En nombre de la libertad, se impidió que se aprobase la obligatoriedad de la asistencia por parte de los poderes públicos. Esta enmienda presentada por la izquierda del Parlamento jugó, por lo tanto, en favor de los que, desde el otro lado del espectro político, disentían también del criterio de la mayoría progresista. De esta forma, el debate sobre sanidad se situó claramente en la dinámica política que, desde 1855 , hizo coincidir a las oposiciones de derecha e izquierda impidiendo la consolidación de la actividad gubernativa progresista ${ }^{4}$. Entre los diputados que votaron contra la obligatoriedad no encontramos tan sólo a los representantes de la izquierda sino también a los de tendencia conservadora, algunos de los que pocos años antes, en 1849, habían aprobado una ley de beneficencia que también coartaba todo intento de imponer la obligatoriedad ${ }^{42}$. A la vista de lo ocurrido en aquella votación, la comisión opinó que si eso no se había aprobado, mucho menos se aprobaría lo que estaba aún por venir. Prefirieron retirar el resto del proyecto y redactarlo de nuevo. Y en la nueva redacción desaparecieron las connotaciones de obligatoriedad que, tal como le había pasado al artículo 74, habrían sido rechazados en el Parlamento 43. No podemos entretenernos a comentar los diferentes aspectos que cambia-

40 DSC, 25-6-1855, p. 5955.

41 CANOVAS SÁNCHEZ, Op. cit.: p. 459: «...durante el verano de 1855 se inició el praceso por el que fue debilitándose cada vez más la begemonia progresista y que culminó con el desplazamiento de Espartero del poder un año despues. Los Gobiernos progresistas fueron bostigados continuamente en las Cortes $y$ los medios de comunicación por la derecha, decidida a obstaculizar la consolidación del Régimen, y por la izquierda radical, que luchaba decididamente para que no se perdiera la oportunidad de realizar neformas demacráticas.»

42 Para poderlo afirmar con rotundidad habría que averiguar la identidad de todos y cada uno de los dipucados que vocaron en uno u otro sencido. De todas formas, parece bastante claro que en general votaron a favor de la enmienda los progresistas más radicales, muchos de los cuales, después del Bienio, se retirarían de la política, serían perseguidos o pasarían a opciones más avanzadas (Alfonso Escalante, Escanislau Figueras, Gil Sanz, Ramón Pérez Costales, Miguel Alegre, ...) y los que en un futuro se apuntarían a Unión Liberal y a las opciones monárquicas durante el Sexenio (Moreno Nieto, Laureà Figuetola, Manuel León Moncasi, Valentín Gil Vírseda, ...). Por otro lado, votaron a favor del proyecto del Gobierno, al margen de sus propios miembros y los hombres más adictos, los que acabarían enfrentándose radicalmente a O'Donnell y a la Unión Liberal ( Pedro Calvo Asensio, Agustín Gómez de la Mata, Hetnández de la Rúa, Santa Cruz, Cantero, ....). Es de destacar además la elevada presencia de médicos y otros facultativos en el gobierno progresista (los casos de Calvo Asensio y Gómez de la Mata, por ejemplo).

${ }_{43}$ Se pueden consultar los artículos nuevamente redactados en el apéndice 12 del número 204 del Diario de Sesiones (pp. 6655-6657).

Hispania, LX/2, núm. 205 (2000) 597-622 
ron. Lo único que no podemos dejar de remarcar es la radicalidad con que fue liquidado el capítulo diecinueve, referente a higiene pública. En el proyecto inicial regulaba en diecinueve artículos diferentes aspectos de la higiene de las poblaciones y, en especial, de las ciudades (cementerios, industrias, mataderos, residuos, etc.). El que más nos interesa, el artículo 126 especificaba claramente que:

«Los Ayuntamientos procurarán que dentro de los pueblos no haya fábricas cuyos materiales y elaboraciones exhalen fetidez y se consideren insalubres.»

En el nuevo redactado, no sólo desaparece este artículo sino también todos los demás del capítulo. En su substitución sólo se incluyó un escueto artículo 101 que decía:

*Las reglas higiénicas a que estarán sujetas todas las poblaciones del reino, serán objeto de un reglamento especial, que publicará el Gobierno a la mayor brevedad, oyendo antes al Consejo de Sanidad»

Como lo realmente breve fue el Gobierno progresista, este reglamento nunca se redactó ${ }^{44}$. Y no puede decirse que fuera debido a un supuesto desinterés y falta de preocupación por estos temas en la época. Precisamente, aquel mismo año, la Academia de Medicina y Cirugía de Barcelona había decidido otorgar un premio al mejor trabajo dedicado a "iQué medidas bigiénicas puede dictar el Gobierno a favor de las clases obreras?", que ganó, como es sabido, un trabajo de Monlau en que se proponían medidas que iban bastante más allá de las dispuestas no tan sólo por la ley aprobada sino también por el proyecto inicial45. Después de ofrecer un análisis muy detallado de los problemas higiénicos

44 En la edición de 1891 del diccionatio Alcubilla, al tratar el tema de salubridad y peligrosidad en los establecimientos industriales, aún se lee que a...entre nosotros no bay disposiciones legislativas que, tomando en cwenta lo pelignoso, incómado e insalubre de ciertos ertablecimientos, exijan para ponerlos dentro de poblado, ni la axtorizacion ni la vigilancia de la Administracion. Hase dijado este importante ramo del servicio administrativo a las Ordenanzas municipales, $y$ como son muchas las poblaciones que no las tienen, 0 que teniéndolas no se ajustan a las nesesidades de la época, se advierte, naturalmente, en este punto, una gran diferencian.

45 MONLAU, Pedro Felipe: Higiene industrial. ¿Qué medidas bigiénicas puede dictar el Gobierno a favor de las clases obreras?, Madrid, Rivadeneyra, 1856 (Hay una edición reciente en MONLAU, P.F. SALARICH, J.: Condiciones de vida y trabajo obrero en España en el siglo XIX. Estudio preliminar y notas de Antoni Jutglar, Barcelona, Anthropos, 1984). Antes del trabajo de Monlau, de todas formas, incluso fuera del ámbito industrial barcelonés, enconcramos apreciaciones similares a las de Monlau, como por ejemplo en SEOANE, M.: Proyecto de Cádigo Sanitario para la Monarquía española, Madrid, 1822, in LOPEZ PÑNERO, J.M.: Op. cit. . Pero no sólo desde posturas progresistas, sino que, también desde el moderancismo, el antes citado Andrés Borrego se planté la problemática industrial, Vid. BORREGO, A.: Organización indsutrial. Exposición y medios, in «La Revista Peninsularm, marzo 1838 (Citado y reproducido en CASTRO, C. de: Op. cit.). 
generados por varios procesos industriales, Monlau concretó en veinte puntos sus propuestas para mejorar la higiene y la salubridad en el trabajo industrial y en la vida obrera:

1.- Descentralizar fábricas y talleres.

2.- Construir los establecimientos industriales de acuerdo con criterios de salubridad.

3.- Construir casas-modelo, con habitaciones adecuadas a los obreros.

4.- Construir lavaderos y casas de baño públicas, económicas o gratuitas.

5.- Proporcionar alimentos de primera necesidad, baratos y abundantes.

6.- Perseguir las adulteraciones de alimentos.

7.- Vigilar la salubridad de tabernas y fondas.

8.- Redactar una ley sobre el trabajo de niños en las fábricas.

9.- Evitar y remediar los accidentes laborales.

10.- Evitar la competencia en los trabajos realizados por centros benéficos.

11.- Abrir paseos y jardines en barrios obreros.

12.- Establecer casas-cuna y asilos.

13.- Establecer escuelas de primeras letras para niños obreros.

14.- Establecer escuelas dominicales para obreros adultos.

15.- Distribuir gratuitamente una cartilla bigiénica para los obreros de cada oficio.

16.- Adjudicar premios anuales a los descubridores de medidas higiénicas.

17.- Establecer cajas de aborro en todos los pueblos importantes.

18.- Fomentar las sociedades de socorros mutuos.

19.- Facilitar asistencia médica gratuita y socorros domiciliarios para los obreros.

20.- Elaborar una estadística sobre el estado de las clases fabriles.

Además, Monlau detallaba los principales problemas higiénicos que presentaba cada tipo de trabajo industrial. En el redactado de la ley, de todas formas, no se hizo caso de sus sugerencias. Es cierto que por entonces Monlau ya formaba parte de una heterodoxia cuyas opciones contaban muy poco en la acción política del liberalismo español, incluso durante la interinidad progresista. Pero a pesar de todo, no hay que olvidar el prestigio de su criterio en materia de higiene. Recordemos que sus Elementos de Higiene Pública, editados por vez primera en 1847, fueron el manual oficial de esta asignatura en la universidad española, con tanto éxito que fueron reeditados y revisados en 1862 y en 1871 . A pesar de ello, el propio autor tenía, en esta edición, palabras bastante duras contra la acción pública española en materia de higiene, sobre todo al recordar lo que pasó durante el Bienio, cuando, tras largos años de espera, existía la oportunidad de elaborar una buena normativa sanitaria e industrial: 
«Con fecha del 8 de octubre de 1855 , presentó el ministro de Fomento a las Cortes un proyecto de ley sobre el ejercicio, la policía, las sociedades, jurisdicción e inspección de la industria manufacturera. De 25 artículos constaba dicho proyecto, y de ellos tres tan sólo hacían teferencia a medidas esencialmente higiénicas: el 7, sobre el trabajo de niños en las fábricas y talleres, el 12, que hablaba, aunque muy en general, de las condiciones de capacidad y salubridad de los establecimientos industriales; y el 13 , que versaba sobre la indemnización a los obreros víctimas de algún accidente desgraciado por culpa de los fabricantes. El proyecto de ley en cuestión se ha quedado hasta ahora en proyecto, y nada se ha hecho. Cuando las circunstancias apremien, fuerza será hacer algo; y entonces peligra mucho que, como de costumbre, se haga todo mal»46.

Es sabido que los gobiernos de Madrid tenían poca conciencia y poco interés en conocer el carácter y las dimensiones de los problemas generados por la industria. Los ejecutivos del Bienio, de todas formas, fuese por mayor sensibilidad o forzados por las circunstancias sociales y de orden público, tuvieron que plantearse la problemática industrial como ningún otro gobierno español había hecho hasta entonces ${ }^{47}$. De cualquier forma, el distanciamiento de estos gobiernos respecto a los cambios que por aquel entonces acontecían era lo bastante nototio como para que incluso algún ministro de Fomento hiciese gala de un pensamiento económico lamentablemente superficial ${ }^{48}$.

Como en el conjunto del Estado, en esta época, la industrialización aún no había comportado demasiados problemas, los únicos que podrían haber salido en defensa de una legislación más completa en este sentido eran los diputados catalanes. Ni tan siquiera los más implicados en temas industriales lo hicieron. Cuando hablaba Laureà Figuerola, entonces destacado portavoz parlamentario

46 MONLAU, P. F.: Elementos de Higiene Pública, o arte de conservar la salud de los pueblos, Madrid, Rivadeneyra, 1862 (1a. ed., 184́7), vol. II, p. 700.

47 En este sentido se llegó a presentar, el 8 de octubre de 1855, como es sabido, el proyecto de ley, antes citado por Monlau, sobre «Ejercicio, policia, sociedades, jurisdicción e inspección de la industria manufacturera", evidentemente motivado por los conflictos del verano anterior. De todas formas, el proyecto quedó completamente estancado en la comisión que debía estudiarlo $y$, a pesar de los requerimientos de diferentes diputados, no llegó a discutirse nunca en el Parlamento. Se puede consultar el desarrollo del proyecto en DSC, 1854-56, pp. 7032, 7045-49, 7055, 7276, 9486, 9503, 10902 y 12763. Un buen estudio del proceso en BENET, J. - MARTí, C.: Barcelona a mitjan segle XIX. El moviment obrer durant el Bienni Progressista (1854-1856), Barcelona, Curial, 1976, Vol. I, Cap. 3: El projecte de llei sobre la industria manufacturera.

48 DSC, 1854-56, pp. 4927-4928. El ministro Francisco Luxan se arrevio a decir que w...en todo país debe baber una justa proporción entre la industria fabril y la industria que produce sustancias alimenticiar. ¿Qué sucede en los pueblos donde se ban llevado al exceso los descubrimientos de la industria, en Inglaterra, por sjemplo? Que tienen que ir a buscar las subssancias alimenticias en los países donde se dan en abundancia y que no son tan industriosos, por eso tienen que ir a Odessa, tienen que ir al Africa, tienen que venir a España, (...). En Cataluña, donde la industria ba tomado un gran desarrollo, como el pats no da bastantes sustancias alimenticias para mantener a todos sus babitantes, tienen que acudir por cereales a Andalucia, a Castilla, a Extremaduras.

Hispania, LX/2, núm. 205 (2000) 597-622 
de los intereses industriales desde las filas del progresismo, quedaba claro que el objetivo fundamental de los fabricantes en el Parlamento consistía sólo en intentar moderar y reconducir las relaciones empresario-trabajador y garantizar la libertad de industria y de contratación. Ya lo explicaron hace unos años Josep Benet y Casimir Martí al citar la felicitación que la Junta de Fábricas hizo liegar a Figuerola después de la interpelación a las Cortes Constituyentes de junio de 1855: pretendía reducir los conflictos sociales derivados de la industrialización a un problema de orden público, promovido por «excitaciones reprobables». Nunca se refería a las malas condiciones de vida de las clases populares en la nueva realidad industrial ${ }^{49}$. Parece lógico pensar que cualquier intento de acción estatal en favor del control de la salubridad fabril debía ser visto desde esta optica como una más de las muchas amenazas a la libertad empresarial. Pero cuando tocaba discutir la ley de sanidad, donde estas cuestiones eran aún más difíciles de obviar que no en el debate sobre industria, ninguno de estos parlamentarios las plantearon. Si exceptuamos unos comentarios muy marginales de Figuerola que en ningún modo cuestionaban la leyso, ninguno de los diputados por Barcelona hizo uso de la palabra a lo largo del debate. El resultado fue que se acabó aprobando una ley de sanidad que dejaba un inmenso vacío en materia de higiene industrial, entre tantos otros aspectos ${ }^{51}$. Durante los casi cincuenta años en que estuvo vigente la ley, la acción pública en materia de sanidad, para bien y para mal, se movió entre los parámetros que entonces se aprobaron. Desde este punto de vista, parece difícil seguir defendiendo que el retraso español en materia social es sólo atribuible a la inoperancia de unos gobiernos madrileños alejados de las vicisitudes del mundo industrial, porque a pesar que sea cierto que estos problemas les quedaban muy lejos, es innegable que pusieron sobre la mesa proyectos legislativos que habrían permitido enfrentarse a ellos si los industriales y los políticos que más implicados estaban en ello así lo hubiesen querido.

49 BENET, J. - MARTí, C.: Op. cit., p. 5482 y ss.

so DSC, 8-6-1855, p. 5482 y ss.

s1 Sirva como ejemplo mi trabajo, citado anteriormente, sobre Sant Martí de Provençals como suburbio industrial de Barcelona, donde se refleja claramente el gran número de denuncias que la administración municipal recibía sobre el mal estado y la insalubridad del trabajo de muchas fábricas y, en especial, de sus resíduos. Estos problemas específicamente fabriles difícilmente podían encontrar respuesta en una legislación que había acabado obviando todo tipo de referencia al trabajo industrial. 